\title{
Laparoscopic Surgery for Meckel's Diverticulum Presenting as Small Bowel Obstruction: A Case Report
}

\author{
Mushtaq Chalkoo*, Mumtaz-Din Wani, Hilal Makhdoomi, Ankush Banotra, Yassar Arafat, \\ Awhad Mueed, Syed Shakeeb
}

Department of General Surgery, Government Medical College, Srinagar, India

Email: *mushtaq_chalkoo@rediffmail.com

How to cite this paper: Chalkoo, M., Wani, M.-D., Makhdoomi, H., Banotra, A., Arafat, Y., Mueed, A. and Shakeeb, S. (2016) Laparoscopic Surgery for Meckel's Diverticulum Presenting as Small Bowel Obstruction: A Case Report. Surgical Science, 7, 505-510. http://dx.doi.org/10.4236/ss.2016.711067

Received: September 27, 2016

Accepted: October 28, 2016

Published: November 1, 2016

Copyright $\odot 2016$ by authors and Scientific Research Publishing Inc. This work is licensed under the Creative Commons Attribution International License (CC BY 4.0).

http://creativecommons.org/licenses/by/4.0/

\begin{abstract}
Meckel's diverticulum is not commonly encountered surgical entity and presents unique challenges for a pediatric surgeon, as it is prone to varied complications. A 14-year-old boy was admitted with us with a 48-hour history of lower abdominal pain and multiple episodes of vomiting. Radiological imaging studies revealed a high-grade partial small bowel obstruction. A fleeting conservative management was tried. The diagnostic laparoscopy revealed a small bowel obstruction secondary to a Meckel's diverticulum. The diverticulum was resected using an endovascular GIA stapler. The patient was discharged on postoperative day four, tolerating a regular diet. Laparoscopy is a useful diagnostic and therapeutic means for a patient with a small bowel obstruction due to an uncertain etiology.
\end{abstract}

\section{Keywords}

Laparoscopy, Meckel's Diverticulum, Small Bowel

\section{Introduction}

A Meckel diverticulum is an embryologic abnormality that is part of a spectrum of anomalies known as yolk stalk or omphalomesenteric duct remnants. Fabricus Hildanus first described a Meckel diverticulum in 1598. In 1809, Johann Meckel, an anatomist, described this anomaly in detail. He identified the origin of the diverticulum as the omphalomesenteric duct and emphasized that this anatomic abnormality was a potential cause of disease. In 1904, Salzer became the first to identify ectopic mucosa within the diverticulum. Meckel's diverticulum is the most commonly encountered congenital anomaly of the small intestine. Its incidence is usually quoted as approximately $2 \%$ of 
the population, but the prevalence can vary from $0.2 \%$ to $2 \%$ [1]. The male to female ratio of symptomatic diverticulum is 3:1. Meckel's diverticulum can present as abdominal pain with an unclear cause, hematochezia, inflammation with or without perforation, intussusception, and a small bowel obstruction [2] [3]. Inflammation of this Meckel's diverticulum may mimic appendicitis. Therefore, during appendectomy, ileum should be checked for the presence of Meckel's diverticulum. If it is found to be present, it should be removed along with appendix. It can also be present as an indirect hernia, typically on the right side, where it is known as, Littre's hernia. Laparoscopy can be used both as a diagnostic and therapeutic tool in children with a small bowel obstruction. We present a case of a small bowel obstruction secondary to a Meckel's diverticulum, diagnosed and treated laparoscopically.

\section{Case Report}

A 14-year-old male, born of non-consanguineous marriage presented with a 48-hour history of lower abdominal pain and multiple episodes of vomiting. The boy was admitted in our emergency department and observed. His biochemical parameters were not suggestive of any intra-abdominal infection or obstruction except mildly elevated leucocytosis. The boy did not exhibit much of clinical signs except mild central abdominal distension. Initial abdominal films revealed multiple air fluid levels (Figure 1). An uppergastrointestinal series (CT-enterography) was performed which revealed poor filling of the terminal ileum consistent with a high-grade partial small bowel obstruction (Figure 2). Fleeting conservative trial was given to the patient but with unsatisfactory results. A diagnostic laparoscopy was performed. A, $10 \mathrm{~mm}$ optical trocar was placed at the level of umbilicus in left midclavicular line via closed technique after veres insertion and pneumoperitoneum insufflation. Two $5 \mathrm{~mm}$ ports were placed, one in the left upper quadrant, anterior axillary line, and one in the left lower quadrant, anterior axillary line. A Meckel's diverticulum with a thick band from the tip of the diverticulum

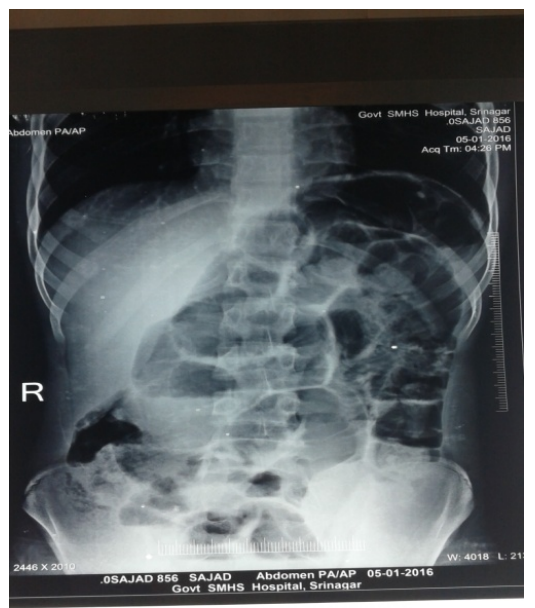

Figure 1. X ray abdomen showing air fluid levels. 
to the small bowel mesentery creating the obstruction was discovered. An obvious transition zone in the distal ileum existed at this point of internal small bowel herniation. We converted left upper quadrant $5 \mathrm{~mm}$ port to $12 \mathrm{~mm}$ stapler port. The diverticulum was resected using an endovascular GIA stapler (Figures 3-7). The patient was discharged home on postoperative day four, tolerating a regular diet. The patient was followed up in our outpatient department at the end of first week with satisfactory results.

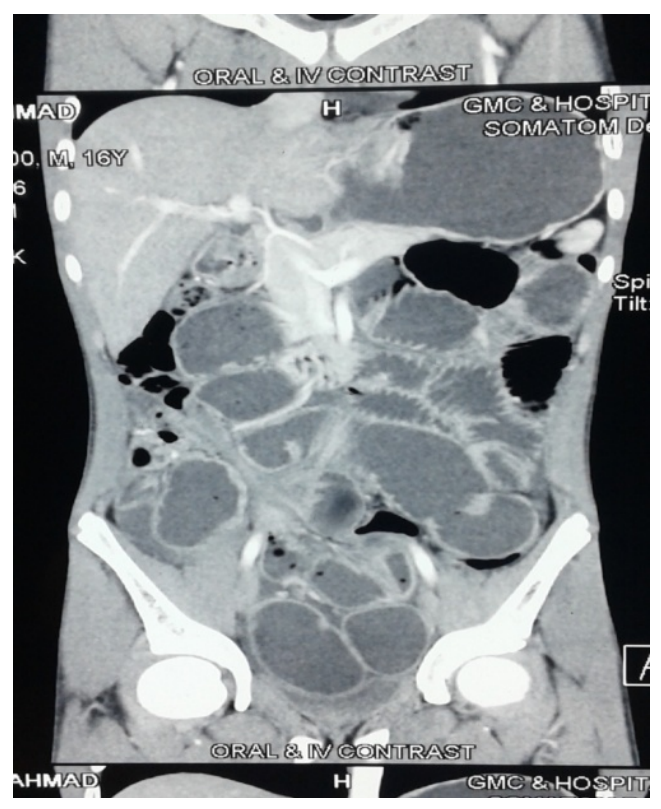

Figure 2. Ct enteroclysis showing distended small bowel.

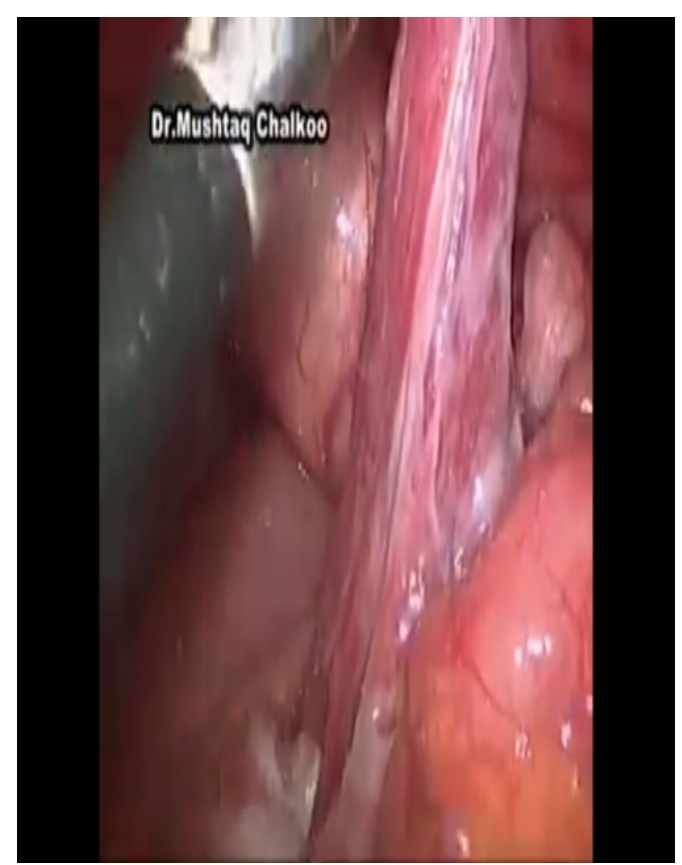

Figure 3. Showing Meckel's diverticulum. 


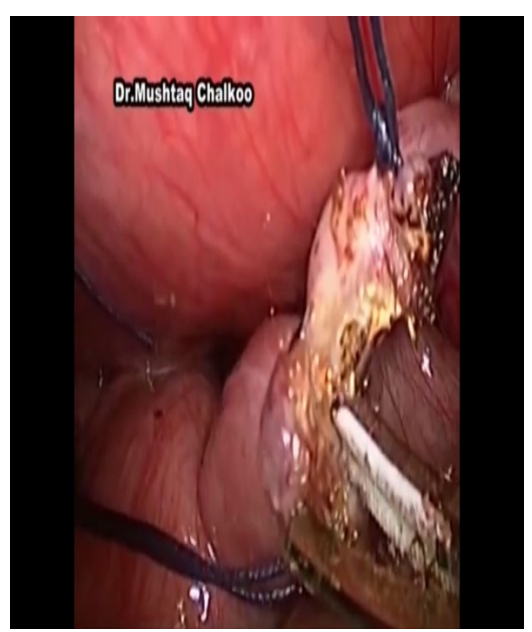

Figure 4. Showing Meckel's band sutured and cut.

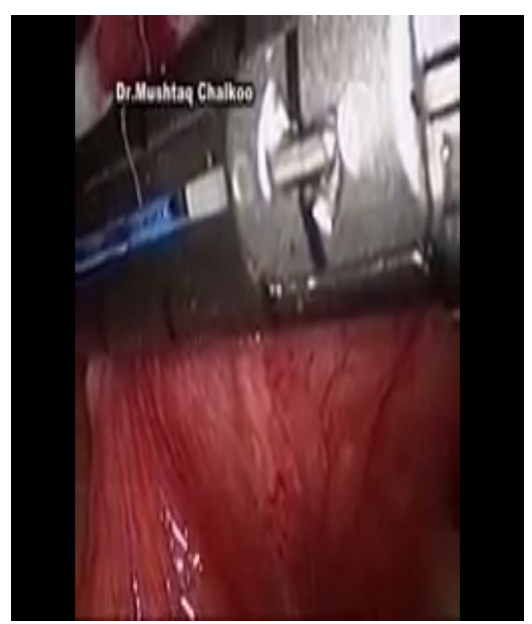

Figure 5. Showing Meckel's diverticulum being stapled.

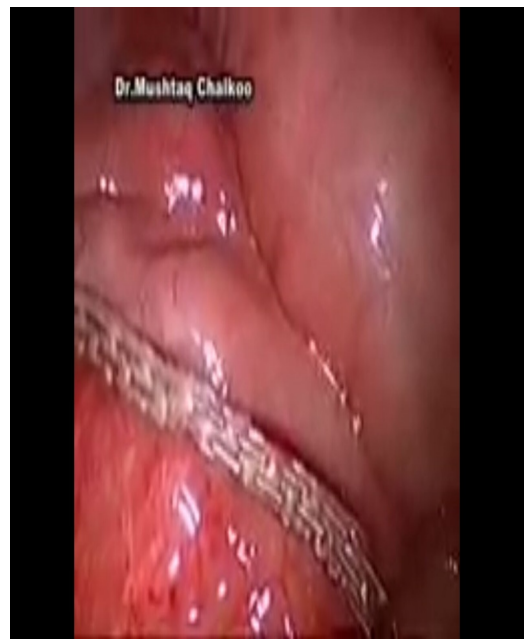

Figure 6. Showing staple line. 


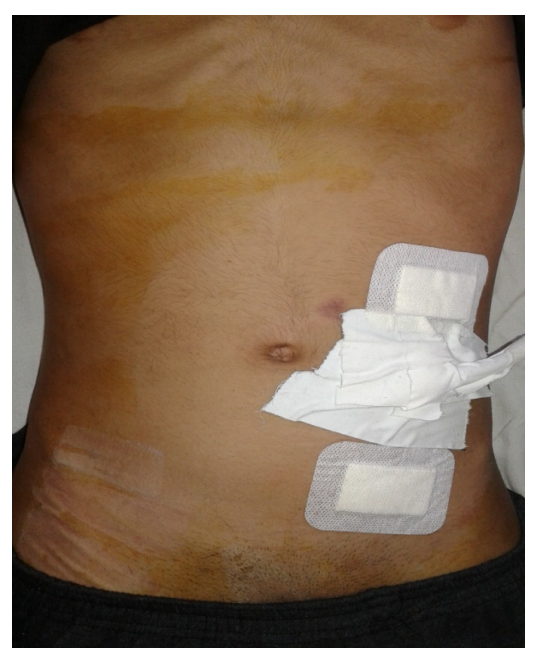

Figure 7. Showing port position.

\section{Discussion}

In many patients with small bowel obstruction, a definitive preoperative cause cannot be determined and if not relieved with nonoperative management; it demands surgery to prevent bowel compromise. Laparoscopy provides a tool to diagnose the cause of the obstruction and often to relieve the obstruction without laparotomy [3] [4].

Small bowel obstruction secondary to a Meckel's diverticulum most often results from intussusception or from herniation of bowel around a diverticular band [2]. Laparotomy is warranted to diagnose and treat these conditions. Attwood et al. [5] initially described resection of a Meckel's diverticulum using laparoscopy. Laparoscopic assisted transumbilical Meckel's diverticulectomy is a simple, safe technique for the precise assessment of the complications of Meckel's diverticulum and performing the resection [6]-[8]. Successful resection of a Meckel's diverticulum can be accomplished through laparoscopy, using endost apling devices [8]. With the advent of gastrointestinal stapling devices, excision has become safer, faster, and more efficient. In two of the cases, a diagnostic laparoscopy was performed to determine the cause of a bowel obstruction and subsequently diverticulectomy was performed.

In our case laparoscopy was performed for diagnostic and therapeutic purposes. We introduced pneumoperitoneum through veress technique. We maintained gentle pressure for insertion of our trocars as the space was very less. Laparoscopic access via an open technique helps minimize the risk of bowel perforation associated with a Veress technique. Laparoscopy also permits inspection of the remainder of the abdomen with reduced postoperative pain and potentially a decreased length of hospital stay. In cases of small bowel obstruction with an uncertain etiology, laparoscopy is an excellent diagnostic tool. When a Meckel's diverticulum is found as the cause of obstruction, laparoscopy also serves therapeutic purpose, obviating the need for laparotomy.

\section{Conclusion}

We recommend that in patients of small bowel obstruction one can give a trial of diag- 
nostic laparoscopy to evaluate the cause and to treat it laparoscopically. However, we also feel such procedures should only be taken up by the most experienced surgeon and low threshold for conversion to open should be exercised as there is compromised space in the abdominal cavity.

\section{References}

[1] Shalaby, R.Y., Soliman, S.M., Fawy, M. and Samaha, A. (2005) Laparoscopic Management of Meckel's Diverticulum in Children. Journal of Pediatric Surgery, 40, 562-567. http://dx.doi.org/10.1016/j.jpedsurg.2004.11.032

[2] Sanders, L.E. (1995) Laparoscopic Treatment of Meckel's Diverticulum. Surgical Endoscopy, 9, 724-727. http://dx.doi.org/10.1007/bf00187950

[3] Teitelbaum, D.H., Polley, T.Z. and Obeid, F. (1994) Laparoscopic Diagnosis and Excision of Meckel's Diverticulum. Journal of Pediatric Surgery, 29, 495-497. http://dx.doi.org/10.1016/0022-3468(94)90075-2

[4] Adams, S., Wilson, T. and Brown, A.R. (2003) Laparoscopic Management of Acute Small Bowel Obstruction. Aust NZ J Surg, 63, 39-41. Journal of the Society of Laparoendoscopic Surgeons, 7, 253-255.

[5] Attwood, S.E.A., McGrath, J., Hill, A.D.K., et al. (1992) Laparoscopic Approach to Meckel's Diverticulectomy. British Journal of Surgery, 79, 211.

http://dx.doi.org/10.1002/bjs.1800790306

[6] Ng, W.T., Wong, M.K., Kong, C.K. and Chan, Y.T. (1992) Laparoscopic Approach to Meckel's Diverticulectomy. British Journal of Surgery, 79, 973-974. http://dx.doi.org/10.1002/bjs.1800790942

[7] Altinli, E., Pekmezci, S., Gorgun, E. and Sirin, F. (2002) Laparoscopy-Assisted Resection of Complicated Meckel's Diverticulum in Adults. Surgical Laparoscopy Endoscopy \& Percutaneous Techniques, 12, 190-194. http://dx.doi.org/10.1097/00129689-200206000-00012

[8] Lee, K.H., Yeung, C.K., Tam, Y.H., Ng, W.T. and Yip, K.F. (2000) Laparoscopy for Definitive Diagnosis and Treatment of Gastrointestinal Bleeding of Obscure Origin in Children. Journal of Pediatric Surgery, 35, 1291-1293. http://dx.doi.org/10.1053/jpsu.2000.9299

Submit or recommend next manuscript to SCIRP and we will provide best service for you:

Accepting pre-submission inquiries through Email, Facebook, LinkedIn, Twitter, etc. A wide selection of journals (inclusive of 9 subjects, more than 200 journals)

Providing 24-hour high-quality service

User-friendly online submission system

Fair and swift peer-review system

Efficient typesetting and proofreading procedure

Display of the result of downloads and visits, as well as the number of cited articles

Maximum dissemination of your research work

Submit your manuscript at: http://papersubmission.scirp.org/

Or contact ss@scirp.org 